Heugten, C.M. van, Dekker, J., Deelman, B.G., Stehmann-Saris, F.C., Kinebanian, A. A diagnostic test for apraxia in stroke patients: internal consistency and diagnostic value. The

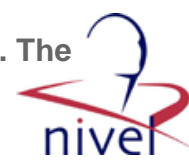

\begin{tabular}{|l|l|}
\hline $\begin{array}{l}\text { Postprint } \\
\text { Version }\end{array}$ & 1.0 \\
\hline Journal website & http://www.tandfonline.com/doi/abs/10.1076/clin.13.2.182.1966 \\
\hline Pubmed link & $\underline{\text { http://www.ncbi.nlm.nih.gov/pubmed?term=10949159 }}$ \\
\hline DOI & $10.1076 /$ clin.13.2.182.1966 \\
\hline
\end{tabular}

This is a NIVEL certified Post Print, more info at http://www.nivel.eu

\title{
A Diagnostic Test for Apraxia in Stroke Patients: Internal Consistency and Diagnostic Value*
}

\author{
Caroline M. van Heugten ${ }^{1,2}$, Joost DeKKeR ${ }^{1,3}$, Betto G. DeElman ${ }^{4}$, FieneKe C. \\ STEHMANN-SARIS ${ }^{5}$, AND ASTRID KINEBANIAN ${ }^{5}$. \\ ${ }^{1}$ Netherlands Institute of Primary Health care (NIVEL), Utrecht, The Netherlands, \\ ${ }^{2}$ Institute for Rehabilitation Research (IRV), Hoensbroek, The Netherlands, \\ ${ }^{3}$ Vrije Universiteit, Amsterdam, The Netherlands, \\ ${ }^{4}$ Department of Neuropsychology, University of Groningen, The Netherlands, and \\ 5Polytechnic of Amsterdam, School for Occupational Therapy, The Netherlands
}

\begin{abstract}
The internal consistency and the diagnostic value of a test for apraxia in patients having had a stroke are presented. Results indicate that the items of the test form a strong and consistent scale: Cronbach's alpha as well as the results of a Mokken scale analysis present good reliability and good scalability. The diagnostic value of the test was determined by comparison of test results in three groups of patients: 44 stroke patients with apraxia (patients), 35 stroke patients without apraxia (patient controls), and 50 healthy nursing home residents with no history of stroke (normal controls). The diagnostic value is expressed by means of the sensitivity and specificity and the predictive value of the test. In addition, Receiver Operator Characteristics (ROC) curves are presented. The sensitivity and specificity of the apraxia test appear to be good: all values are higher than $80 \%$. The test also has high predictive value. The ROC curves illustrate that the test is sufficiently discriminative to allow a differentiation between persons with apraxia and persons without apraxia.
\end{abstract}

Apraxia is one of the classic neuropsychological impairments which can be the consequence of left-hemisphere stroke. For a patient with apraxia, it is difficult or impossible to perform learned purposeful activities of daily living (ADL), which could be performed correctly before the stroke occurred (i.e., skilled activities). These problems in ADL-functioning are the result of the absence or disturbance of a plan of action. These disturbances in the organization of voluntary actions are not due to primary motor or sensory impairments; the patient has, for instance, sufficient muscle strength or motor coordination to perform the actions. Neither are these difficulties the result of lack of motivation, attention, or comprehension. Other 
Heugten, C.M. van, Dekker, J., Deelman, B.G., Stehmann-Saris, F.C., Kinebanian, A. A diagnostic test for apraxia in stroke patients: internal consistency and diagnostic value. The Clinical Neuropsychologist: 1999, 13(2), 182-192

impairments, such as aphasia or hemiplegia, may be present, but these deficits are not the cause of the inability to perform learned, skilled purposeful acts (De Renzi, 1989; Geschwind, 1975; Kolb \& Whishaw, 1990; Rothi \& Heilman, 1997).

In the literature many different classifications and forms of apraxia are described and discussed (Concha, 1987; De Renzi, 1989; Luria, 1966; Roy, 1978; Tate \& McDonald, 1995).

However, there is not one accepted taxonomy and the literature is often inconsistent and confusing.

The first, now classic, theory of apraxia was formulated by Liepmann (1920), in which he proposed three different types (ideational apraxia, motor apraxia, and limbkinetic apraxia). Later, Luria (1966) discussed yet three other forms of apraxia (frontal, premotor, and kinesthetic apraxia). These forms are all associated with the limbs. Apraxia can also be classified in terms of the affected body part, for instance, oral apraxia (Heilman \& Gonzalez- Rothi, 1985). In addition, many forms of apraxia are described in relation to the activity that is disturbed, for instance, constructional apraxia (Kleist, 1934) or dressing apraxia (Brain, 1941).

Many forms of apraxia have been the object of research studies, and some forms have been dismissed or at least disputed.

The present study is restricted to ideational and ideomotor apraxia. These two forms have been the object of many studies in recent years and are sometimes labelled as the two classic forms of apraxia (Tate \& McDonald, 1995). A patient with ideational apraxia does not know what to do: the very concept or idea of the motor act is lacking or not retrievable from memory (De Renzi, 1989; De Renzi \& Lucchelli, 1988).

A patient with ideational apraxia will have problems organizing performance; series of movements get disrupted (Arnadottir, 1990; De Renzi \& Lucchelli, 1988). In ideomotor apraxia the idea or plan of action is not impaired (i.e., the patient does know what to do), but the implementation of the movement sequence into a proper mode of action is disrupted (i.e., the patient does not know how to do it; De Renzi, 1989). Patients with ideomotor apraxia "have difficulty with the selection, sequencing and spatial orientation of movements involved in gestures including emblems and pantomime’' (Heilman \& Gonzalez-Rothi, 1985, p. 134). In the literature the existence and autonomy of these two forms of apraxia have been brought under discussion. At some point in time the claim was made that ideational apraxia is only a severe form of ideomotor apraxia (e.g., Liepmann, 1920; Sittig, 1931; Zangwill, 1960). Others, however, claimed that ideational apraxia is a distinct form of apraxia (De Renzi \& Lucchelli, 1988). Several authors claimed ideomotor apraxia to be merely an artefact of testing performance, because the patient may not be able to perform on request, whereas in a natural setting he or she is able to carry out the same activity perfectly well (De Renzi, Motti, \& Nichelli, 1980). This claim was challenged by other researchers demonstrating disturbances in everyday activities following ideomotor apraxia (Bjorneby \& Reinvang, 1985; De Renzi \& Lucchelli, 1988; Sundet, Finset, \&Reinvang, 1988).

The two forms of apraxia frequently occur together, but because different mechanisms are disrupted and different structures are involved, the two forms should be kept separate, according to De Renzi (1989). This statement can however be disputed. 
Heugten, C.M. van, Dekker, J., Deelman, B.G., Stehmann-Saris, F.C., Kinebanian, A. A diagnostic test for apraxia in stroke patients: internal consistency and diagnostic value. The Clinical Neuropsychologist: 1999, 13(2), 182-192

Measuring or, more specifically, diagnosing apraxia is difficult and standardized tests are not readily available (Kolb \& Whishaw, 1990; Schellekens, 1989; Wade, 1992). The majority of testing procedures for apraxia were developed to elaborate theoretical models and explanations, and were applied in empirical studies. Results of applied research concerning assessment of apraxia are not available. At present, no scoring system for apraxia has been generally accepted, because of uncertainty about what to score and how to score it (Lezak, 1995). Clinicians attempting to diagnose apraxia mainly rely on personal experience, clinical impression, and intuition (Poeck, 1986).

To overcome some of these limitations, a diagnostic procedure for apraxia was developed, based on the ideas of De Renzi (De Renzi et al., 1980, 1982, 1988). The procedure involves a neuropsychological test for apraxia, including tasks for demonstration of object use and imitation of gestures. Typically, ideational apraxia is examined in tests requiring the use of objects, whereas ideomotor apraxia is most commonly tested by asking the patient to imitate gestures (De Renzi, Faglioni, \& Sorgato, 1982; De Renzi \& Luchelli, 1988; De Renzi, Motti, \& Nichelli, 1980). The goal of our test is to facilitate a differentiation between patients with apraxia and patients without apraxia, thereby offering a method to objectify the clinician's impression.

To this end, the apraxia test is part of a diagnostic procedure for apraxia in which the focus is set on the specific observable problems in daily functioning as a result of apraxia. This means that this study is not an attempt to make a theo retical claim or to put forward a new neuroanatomical or neuropsychological model of apraxia. Taking the consequences of apraxia as point of departure, the autonomy of the two forms of apraxia can be discussed. First, the homogeneity of the apraxia test is assessed in order to determine whether the two subtests measure different forms of apraxia. This examination is conducted in order to form a judgement concerning the autonomy of the two forms of apraxia. Second, before actually using the apraxia test it is important to determine its discriminative capacity. In the present study the diagnostic value of the test is described in terms of sensitivity, specificity, and predictive values.

\section{METHODS}

\section{Participants}

Participants comprised the following: two groups of patients who had suffered a left hemisphere stroke (1) patients with apraxia ( $\mathrm{n}=44$; patients) and (2) patients without apraxia ( $\mathrm{n}=35$; patient controls), and nursing home residents with no history of stroke or other central deficits $(n=50$; normal controls). A list of inclusion and exclusion criteria for the selection of patients was offered to the occupational therapists in writing. Inclusion criteria for patients with apraxia were stroke in the left hemisphere in combination with apraxia, diagnosed on the basis of clinical evaluation. Clinical evaluation was done either by the referring physician or by the occupational therapist using methods which were at that moment accepted or prevalent in the participating institutions.

A left-hemisphere stroke is diagnosed when acute clinical symptoms of a focal dysfunction of the left hemisphere are present; these signs and symptoms last at least $24 \mathrm{hr}$, and there is most likely no other than a vascular origin (Van Crevel, 1991; WHO, 1989). Apraxia is diagnosed when the patient is fully or partly unable to carry 
Heugten, C.M. van, Dekker, J., Deelman, B.G., Stehmann-Saris, F.C., Kinebanian, A. A diagnostic test for apraxia in stroke patients: internal consistency and diagnostic value. The Clinical Neuropsychologist: 1999, 13(2), 182-192

out purposeful activities, this neither due to primary motor or sensory impairments, nor to deficits of comprehension, memory, or motivation. Other impairments may be present, but they are not the cause of the inability to perform purposeful acts (Kolb \& Whishaw, 1990). Likewise, the patient controls had survived a left-hemisphere stroke, but had not been diagnosed to have apraxia.

Normal controls suffered no present or previous brain injury. Exclusion criteria for all groups were: age between 25 years and 95 years, no working knowledge of the Dutch language, and a selected set of premorbid or present pathologies: psychiatric or psychogeriatric history, addiction to alcohol, medical or other drugs, contusio cerebri, personality, intellectual or learning disorders, temporary loss of consciousness, or injuries to the central nervous system.

\section{Assessment}

An apraxia test was used on the basis of tests described in the literature (De Renzi et al., 1980, 1982, 1988, 1989). The test consists of two subtests: demonstration of object use and imitation of gestures; these two tasks are the most widely accepted tasks to test for ideational apraxia and ideomotor apraxia respectively (De Renzi et al., 1980, 1982, 1988).

The use of objects, a method for the assessment of ideational apraxia, is tested in three different conditions (De Renzi et al., 1982). Sets of objects are presented to the patient with the same instruction: 'show me how you would use ... (this object)'. Each set contains three objects used in daily activities; (1) key, hammer, and toothbrush; (2) spoon, hammer, and scissors; and (3) eraser, comb, and screwdriver. The first set of objects is presented only by verbal request, without the object present. The second set of objects is presented visually; the participant may look at the objects, but not touch them.With the third set of objects actual use is tested: the objects are handed to the patient, who may see and feel them.

The subtest of imitation of gestures, aimed at ideomotor apraxia specifically, contains the following six gestures to be imitated by the patient immediately upon demonstration by the researcher: sticking out one's tongue, blowing out a candle, closing one's eyes, waving goodbye, saluting, and making a fist (De Renzi et al., 1980).

To avoid interference of motor or sensory impairments the patient groups (patients and patient controls) used the hand ipsilateral to the side of the brain lesion (i.e., the 'healthy' hand, which is the left hand) in both subtests. The normal controls were allowed to use the hand of preference, because De Renzi et al. (1980) found no difference between the performance of normal control patients who used the right hand and those who used the left hand. There are instances where this line of reasoning could lead to a misdiagnosis, but these are clearly exceptions. This concerns patients with callosal lesions who could carry out skilled acts with their non-hemiplegic right hand, but not with their left hand (Graff-Radford, Welsh, \& Godersky 1987; Watson \& Heilman, 1983).

The scoring procedure was based on De Renzi and Lucchelli (1988): the performance is correct and appropriate (3 points); the performance resembles the correct one, but is somewhat imprecise or the patient uses a body part as object ( 2 points); the performance only weakly resembles the correct one but is executed in the correct place, or it is correct but carried out in a wrong place (i.e., moving the toothbrush in front of the forehead; 1 point); and the performance is not correct or so 
Heugten, C.M. van, Dekker, J., Deelman, B.G., Stehmann-Saris, F.C., Kinebanian, A. A diagnostic test for apraxia in stroke patients: internal consistency and diagnostic value. The Clinical Neuropsychologist: 1999, 13(2), 182-192

incomplete that it is not recognizable (0 points). Each participant was asked to perform the activity; if the performance was correct at first attempt, a score of 6 was given. If the execution was not quite correct or even totally wrong, the participant was allowed to try again. The scores of both attempts were added to arrive at a score per item (maximum score of 6). The maximum subscore for demonstration of object use was 54 and for imitation of gestures 36 .

The maximum total score was 90 .

\section{Testing Procedure}

Once patients and patient controls had consented to participate in the study, a diagnostic procedure including the apraxia test was started. The measurements were performed at occupational therapy (OT) departments in general hospitals, rehabilitation centers, and nursing homes in the Netherlands.

Each patient was tested by the experimenter in a 1- hr testing session, during which the test of apraxia and tests for additional impairments were conducted.

The patient sat facing the experimenter in a quiet room suitable for testing. The elderly participants (normal controls) were tested by the experimenter in a session which consisted solely of the test of apraxia. Participation took place on the basis of informed consent. Here too, the person sat facing the experimenter in a quiet room suitable for testing.

\section{Statistical Analyses}

The internal consistency of the apraxia test was assessed by computing Cronbach's alpha, and by performing Mokken scale analysis. Alpha is an indicator of the internal consistency of a test, expressed by the average correlation of the items within the test. The homogeneity of the test is considered to be good if alpha is higher than 0.80 (De Haan, 1994). However, the use of alpha can be misleading, because alpha depends on the number of items in the test (Drenth \& Sijtsma, 1990). Hence, a Mokken scale analysis was added.

Mokken scale analysis is a scaling technique for determining the homogeneity of a scale. The degree to which one or more unidimensional scales are formed is indicated by the scalability coefficient Loevinger's $\mathrm{H}$ (a value of 0.50 or higher represents good scalability), by the reliability coefficient Rho, and by a hierarchical order for the level of difficulty of the items (Mokken, 1971; Mokken \& Lewis, 1982).

The diagnostic value of a test can be expressed by means of its sensitivity and specificity. The sensitivity of a test is expressed by the percentage of patients with a certain disease being classified by the test as 'ill'; the specificity of a test is shown by the percentage of a group of persons not having the disease for which the test was developed being classified by the test as not having the specific disease. Cicchetti, Volkmar, Klin, and Showalter (1995) suggested the following classification for the levels of the indices of diagnostic accuracy: below 70\% denotes poor accuracy, between 70 and $79 \%$ is fair, between 80 and $89 \%$ is good and between 90 and 100\% means excellent diagnostic accuracy. In clinical practice, an important property of a test is its predictive value: the chance that persons with a certain test score actually have the disease. 
Heugten, C.M. van, Dekker, J., Deelman, B.G., Stehmann-Saris, F.C., Kinebanian, A. A diagnostic test for apraxia in stroke patients: internal consistency and diagnostic value. The Clinical Neuropsychologist: 1999, 13(2), 182-192

A positive predictive value describes which part of the persons under study with a positive test score actually have the disease. A negative predictive value describes which part of the persons under study with a negative test score are healthy. In computing these discriminative variables, a cutoff score is needed: a score below this value indicating the presence of the disease. Usually the clinical literature on apraxia gives cutoff points based on the poorest (but-one) score found in normal control patients (De Renzi et al., 1980, 1988).

A person free from brain injury may however yield low scores as a result of clumsiness, which should not be interpreted as an indicator of apraxia. In addition, the optimal cutoff score depends on the situation under which the test is administered. For this reason various possible cutoff scores have been examined in the current study. In test research the mean score of normal controls minus one standard deviation and minus two standard deviations are often used as cutoff points. These two possibilities are both examined. Additionally, the poorest score of normal controls is considered.

The above mentioned quantities can be derived from a $2 \times 2$ table (Table 1 ). The sensitivity is calculated by $a /(a+c)$; the specificity is determined by $d /(b+d)$. The positive predictive value equals $\mathrm{a} /(\mathrm{a}+\mathrm{b})$ and the negative predictive value is calculated by $\mathrm{d} /(\mathrm{c}+\mathrm{d})$.

\section{[TABLE 1]}

The trade-off between the sensitivity and the specificity can be illustrated by a Receiver Operator Characteristics (ROC) curve. An ROC curve is obtained by plotting the sensitivity against the complement of the specificity for each possible cutoff point. The area under the curve represents the overall accuracy: the best discrimination is obtained when a curve approaches the left upper corner.

The discriminative capacity increases as the area increases. This area theoretically ranges from 0.5 (no accuracy, along the diagonal) to 1.0 (perfect accuracy). On the basis of the trade-off between true positives and false positives the decision can be taken concerning the optimal cutoff point to be chosen for a certain application of the test under study.

All statistical analyses were performed using SPSS/PC+, version 5.0, except for the Mokken scale analysis, which was performed using MSP, version 3.0 (Molenaar, 1994).

\section{RESULTS}

\section{Characteristics of the Participants}

The characteristics of the three groups of participants are presented in Table 2. In all groups more females than males participated in the study. In the two patient groups the numbers of females were comparable (patients and patient controls; $p=.48$ ). In the control group the number of females differed significantly from the patient group $(\mathrm{p}=.01)$ as well as from the patient control group $(\mathrm{p}=.09)$. The ages of the participants in the three groups were not comparable (all $\mathrm{p}$ values $=.00$ ); the normal controls were older. The two patient groups did not differ significantly as regards the 
Heugten, C.M. van, Dekker, J., Deelman, B.G., Stehmann-Saris, F.C., Kinebanian, A. A diagnostic test for apraxia in stroke patients: internal consistency and diagnostic value. The Clinical Neuropsychologist: 1999, 13(2), 182-192

type of stroke $(\mathrm{p}=.11)$. Concerning the time since stroke there was a difference of 4.6 weeks between the two groups, but this difference was not significant $(p=.10)$.

\section{Internal Consistency of the Apraxia Test}

In Table 3 the indices representing the homogeneity of the apraxia test are shown. This table is based on the scores of the group of stroke patients with apraxia. The alpha values as well as the results of the Mokken scale analyses presented good reliability and good scalability. The coefficients indicated that the subtests for demonstration and imitation together formed one unidimensional scale; the $\mathrm{H}$ coefficient of the total scale had a value of .72, which indicates a strong scale. The rho-value of the total scale was .97. The H-values of the subtests (.76 for demonstration of object use, and .71 for imitation of gestures) differed only slightly from the $\mathrm{H}$ value of the total scale. This result indicated that the test of apraxia does not consist of two subtests measuring different concepts, but should rather be considered to be a homogeneous test measuring the same underlying construct, most probably being apraxia.

The items could be ordered hierarchically from less difficult to more difficult (Table 4).

For this group of apraxia patients, imitation of gestures was less difficult than demonstration of object use. Within the latter subtest it appeared that actual object use was less difficult than demonstration with the object present, whereas demonstration with the object present was less difficult than demonstration of object use on verbal request only.

\section{Difference Between Groups}

\section{[TABLE 2]}

The results of the apraxia test are shown in Table 5 . As can be seen in the table, the mean value on both subtests - demonstration of object use and imitation of gestures - as well as the total mean score was much lower for the group of stroke patients with apraxia than for the two other groups. A t test showed that the total mean score of the group of patients with apraxia differed significantly from the total mean score of the patient controls $(\mathrm{t}=7.34 ; \mathrm{p}=.000)$ and from the normal controls $(\mathrm{t}=7.56 ; \mathrm{p}=$ $.000)$. The total mean score of patient controls and normal controls did not differ significantly $(\mathrm{t}=1.34 ; \mathrm{p}=.18)$. The standard deviation and the ranges of the patients with apraxia showed considerably more variation than those of the other two groups. for the total test the patient controls did not score below 75. Among the normal controls 78 was lowest score. The patients with apraxia scored across the total range of possible scores (0-90). Sixty-four percent of the patients with apraxia had scores below the lowest score of the patient controls; $70 \%$ of the patients with apraxia had scores at or below the lowest score of the normal controls (Table 6). 
Heugten, C.M. van, Dekker, J., Deelman, B.G., Stehmann-Saris, F.C., Kinebanian, A. A diagnostic test for apraxia in stroke patients: internal consistency and diagnostic value. The Clinical Neuropsychologist: 1999, 13(2), 182-192

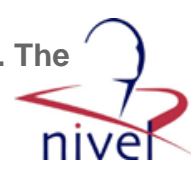

\section{[TABLE 3]}

\section{Sensitivity and Specificity}

The sensitivity and specificity could be derived from the score distribution as presented in Table 6. If the poorest score of normal controls (78) was considered as a cutoff point, the sensitivity of the test was $66 \%$. The specificity of the test was $97 \%$ for the patient controls, and 100\% for the normal controls. [table 4] Based on a cutoff point of the mean score minus one standard deviation (86.4) the sensitivity of the test was $91 \%$. The specificity was $80 \%$ when the patient controls were considered.

For the normal controls the specificity was $90 \%$.

If a cutoff point of the mean score minus two standard deviations (84) was chosen, the sensitivity was $82 \%$. The specificity was $89 \%$ and $96 \%$ for the patient controls and the normal controls, respectively. The optimal cutoff point could be considered on the basis of the classification of Cicchetti et al (1995): the mean score minus one standard deviation (86.4) as well as the mean score minus two standard deviations (84) both showed percentages above $80 \%$, which indicates good to excellent diagnostic accuracy. The optimal cutoff point can additionally be defined as the point with the best combination of the sensitivity and the specificity. This optimum could be determined by averaging the sensitivity and the specificity for each cutoff point; the highest mean value could be considered optimal. For our data this optimum appeared to be a cutoff point of 86, which is the mean score minus one standard deviation. [table 5 ] [table 6] The trade-off between the sensitivity and the specificity was illustrated by presenting a ROC curve. In Figure 1 two ROC curves are shown: one for the scores of the patients with apraxia and the patient controls, and one for the scores of the patients with apraxia and the normal controls.

Both curves approached the upper left corner, producing a large area under the curve.

\section{Predictive Values}

The positive and negative predictive values of the apraxia test were calculated on the basis of the score distribution in Table 6. If a cutoff point of the poorest score of normal controls (78) was considered, the positive predictive value was $97 \%$ for the patient controls and $100 \%$ for the normal controls. The negative predictive values were $69 \%$ and $77 \%$ for the patient controls and the normal controls respectively. If a cutoff point of the mean score minus one standard deviation (86.4) was chosen, the positive predictive value was $87 \%$ for the patient controls and $89 \%$ for the normal controls. The negative predictive values were $88 \%$ and $92 \%$ for the patient controls and the normal controls respectively. If a cutoff point of the mean score minus two standard deviations (84) was chosen, the positive predictive value was $90 \%$ for the patient controls and $95 \%$ for the normal controls; the negative predictive values were $79 \%$ for the patient controls and $86 \%$ for the normal controls. 
Heugten, C.M. van, Dekker, J., Deelman, B.G., Stehmann-Saris, F.C., Kinebanian, A. A diagnostic test for apraxia in stroke patients: internal consistency and diagnostic value. The Clinical Neuropsychologist: 1999, 13(2), 182-192

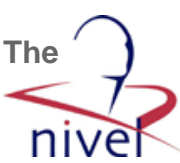

\section{DISCUSSION}

This paper presents the results of a study of a test for apraxia in patients having had a stroke.

The assessment of the homogeneity of the test shows that the diagnosis of apraxia is possible on the basis of the total score: the two subtests together measure the same underlying construct.

Nevertheless, the subtest imitation of gestures seems to cause less difficulty in performance than the subtest demonstration of object use.

\section{[FIGURE 1]}

The items of the two subtests for demonstration of object use and imitation of gestures can be combined into one strong and consistent scale. This implies that both subtests measure the same underlying concept. In other words, the test of apraxia can not be used for distinguishing between ideational and ideomotor apraxia. Or, to put it differently, the two forms of apraxia are not autonomous forms. This result does not confirm suggestions of some authors that both forms of apraxia can occur separately (e.g., De Renzi \& Lucchelli, 1988; Poeck, 1985), although it is not impossible that in another group of patients with apraxia the dissociation between the two forms of apraxia would be apparent. Indeed, there are studies investigating apraxia in patients having other forms of brain damage showing either cases of ideational apraxia (Ochipa, Gonzalez Rothi, \& Heilman, 1992) or ideomotor apraxia (Shelton \& Knopman, 1991).

Additionally, our claim is based on a group of patients and therefore it is conceivable that in case studies investigating single patients, the two forms of apraxia are found independently.

Our data indicate that the example set by Dee, Benton, and van Allen (1970), Kimura and Archibald (1974) and later by Lezak (1995) should be followed: it is more appriopriate to use descriptive terminology (e.g., observable problems in functioning) than distinguishing different forms of apraxia in theoretical terms. The diagnostic value was expressed by means of the sensitivity and the specificity on the one hand, and the positive and negative diagnostic values on the other. The results indicate that the sensitivity and the specificity of the test are good. This conclusion is illustrated by the ROC curves, which depict the interaction between the indices: the areas under the curves are close to 1.0, indicating that the test shows sufficient discriminative capacity. This implies that the apraxia test enables us to differentiate between persons with apraxia and persons without apraxia. The ROC curve then supports a decision on where the best cutoff point would be for a certain application (Jelles \& Bennekom, 1995). On the basis of the current data, a cutoff score of the mean score minus one standard deviation is recommended for the apraxia test.

This score can be considered optimal in terms of the best combination of the sensitivity and specificity.

However, in present daily practice the prevalence of apraxia is overestimated: stroke patients experiencing problems in the execution of daily activities are sometimes 
Heugten, C.M. van, Dekker, J., Deelman, B.G., Stehmann-Saris, F.C., Kinebanian, A. A diagnostic test for apraxia in stroke patients: internal consistency and diagnostic value. The Clinical Neuropsychologist: 1999, 13(2), 182-192

wrongly classified as apractic. In other words, the test must diminish false positives and therefore be highly specific. This would argue in favour of the mean score minus two standard deviations. The situation under which the test is applied will have to guide the actual decision on the optimal cutoff point.

For the development of a diagnostic test, Feinstein (1985) recommends a procedure with several phases: in the first phase a maximal contrast is established by testing patients and healthy controls; in the second phase a patientcontrol design is used. In our study both possibilities are explored. Indeed, our conclusions are based on tests involving three groups of participants: stroke patients with apraxia, stroke patients without apraxia, and healthy elderly persons.

Comparison between the groups could be influenced by the age of the normal controls: the normal controls are considerably older than the participants in the two patient groups. This difference however, reinforces our conclusions concerning the specificity of the test for apraxia: despite the high age of the normal controls, the discriminative capacity of the test is good.

In conclusion, the apraxia test presented in this paper offers a simple and consistent instrument.

This instrument makes it possible to distinguish between patients with apraxia and patients without apraxia, as indicated by its discriminative capacity. An important aspect which should be investigated next is the interrater reliability of the instrument: to what extent do two observers reach the same conclusions when observing the same performance?

\section{REFERENCES}

Arnadottir, G. (1990). The brain and behaviour. St. Louis, MO: Mosby Company. Bjorneby, E.R., \& Reinvang, I.R. (1985). Acquiring and maintaining self-care skills after stroke. Scandinavian Journal of Rehabilitation Medicine, 17, 75-80.

Brain,W.R. (1941). Visual disorientation with special reference to lesions in the right cerebral hemisphere. Brain, 64, 244-272.

Cicchetti, D.V., Volkmar, F., Klin, A., \& Showalter, D. (1995). Diagnosing autism using ICD10 criteria: A comparison of neural networks and standard multivariate procedure. Child Neuropscyhology, 1, 26-37.

Concha, M.E. (1987). A review of apraxia. British Journal of Occupational Therapy, 50, $222-$ 226.

Crevel, H., van (1991). Consensus cerebro vascular accident. Nederlands Tijdschrift voor Geneeskunde, 135, 48, 2280-2288.

Dee, H.L., Benton, A.L., \& Van Allen, M.W. (1970) Apraxia in relation to hemisphere locus of lesion and aphasia. Transactions of the American Neurological Association, 95, 147-148.

De Renzi, E. (1989). Apraxia. In F. Boller \& J. Grafman (Eds.), Handbook of neuropsychology, 2 (pp. 245-263). Amsterdam: Elsevier Science Publishers.

De Renzi, E., Faglioni, P., \& Sorgato, P. (1982). Modality- specific and supramodal mechanisms of apraxia. Brain, 105, 301-312.

De Renzi, E., \& Lucchelli, F. (1988). Ideational apraxia. Brain, 111, 1173-1185.

De Renzi, E., Motti, F., \& Nichelli, P. (1980). Imitating gestures: A quantitative approach to ideomotor apraxia. Archives of Neurology, 37, 6-18.

Drenth, P.J.D., \& Sijtsma, K. (1990). Testtheorie: Inleiding in de theorie van de psychologische test en zijn toepassingen [Testing theory: Introduction into the theory of the psychological test and its applications]. Houten/Zaventem, The Netherlands: Bohn Stafleu van Loghum.

Feinstein, A.R. (1985). Clinical epidemiology: The architecture of clinical research. Philadelphia:WB Sanders. Geschwind, N. (1975). The apraxias: Neural mechanisms of disorders of learned movement. American Scientist, 63, 188-195. 
Heugten, C.M. van, Dekker, J., Deelman, B.G., Stehmann-Saris, F.C., Kinebanian, A. A diagnostic test for apraxia in stroke patients: internal consistency and diagnostic value. The Clinical Neuropsychologist: 1999, 13(2), 182-192

Graff-Radford, N.R., Welsh, K., \& Godersky, J. (1987). Callosal apraxia. Neurology, 37, 100105.

Haan, R., de. (1994). Clinimetrics in stroke [dissertation]. University of Amsterdam, Amsterdam.

Heilman, K.M., \& Gonzalez-Rothi, L.J. (1985). Apraxia. In K.M. Heilman \& E. Valenstein (Eds.), Clinical neuropsychology (2nd ed). Oxford: Oxford University Press.

Jelles, F., \& Bennekom, C.A.M. (1995). Rehabilitation Activities Profile. The ICIDH as a framework for a problem-oriented assessment method in rehabilitation medicine [dissertation]. Free University, Amsterdam.

Kimura, D., \& Archibald, Y. (1974). Motor functions of the left hemisphere. Brain, 97, 337350.

Kleist, K. (1934). Gehirnpathologie vornehmlich auf Grund der Kriegerfahrungen. [Brain pathology, mainly on the basis of war experiences.] Leipzig: Barth.

Kolb, B., \& Whishaw, I.Q. (1990). Fundamentals of human neuropsychology (3rd ed.). New York: Freeman.

Lezak, M.D. (1995). Neuropsychological assessment (3rd ed.). New York: Oxford University Press.

Liepmann, H. (1920). Apraxie. [Apraxia.] Ergebnisse der Gesamten Medizin, 1, 516-543.

Luria, A.R. (1966). Higher cortical functions in man. New York: Basic Books.

Mokken, R.J. (1971). A theory and procedure of scale analysis. Den Haag: Mouton.

Mokken, R.J., \& Lewis, C. (1982). A nonparametric approach to the analysis of dichotomous item responses. Applied Psychological Measurement, 6(4), 417-430.

Ochipa, C., Gonzalez Rothi, L.J., \& Heilman, K.M. (1992). Conceptual apraxia in Alzheimer's disease. Brain, 115, 1061-1071.

Poeck, K. (1985). Clues to the nature of disruptions to limb apraxia. In E.A. Roy (Ed.), Neuropsychological studies of apraxia and related disorders (pp. 99-110). Amsterdam: North Holland.

Poeck, K. (1986). The clinical examination for motor apraxia. Neuropsychologia, 24, 129134.

Rothi, L.J.G., \& Heilman, K.M. (1997). Apraxia: The neuropsychology of action. Hove: Psychology Press.

Roy, E.A. (1978). Apraxia: A new look at an old syndrome. Journal of Human Movement Studies, 4, 191-210.

Schellekens, J.M.H. (1989). Classificatie en diagnostiek van stoornissen in de praxis [Classification and assessment of impairments in the praxis]. Bewegen \& Hulpverlening, 1, 4-21.

Shelton, P.A., \& Knopman, D.S. (1991). Ideomotor apraxia in Huntington's disease. Archives of Neurology, 48, 35-41.

Sittig, O. (1931). Uber apraxie: Eine Klinische Studie. [About apraxia: A clinical study.] Berlin: Krager.

Sundet, K., Finset, A., \& Reinvang, I.R. (1988). Neuropsychological predictors in stroke rehabilitation.

Journal of Clinical and Experimental Neuropsychology, 10, 363-379.

Tate, R.L., \& McDonald, S. (1995). What is apraxia? The clinician's dilemma.

Neuropsychological Rehabilitation, 5(4), 273-297.

Wade, D.T. (1992). Measurement in neurological rehabilitation. Oxford: Oxford University Press.

Watson, R.T., \& Heilman, K.M. (1983). Callosal apraxia. Brain, 106, 391-403.

World Health Organization, special Report (1989).

Stroke-1989. Recommendations on Stroke Prevention, Diagnosis, and Therapy. Stroke, 20, 1407- 1431.

Zangwill, O.L. (1960). Le probleme de l'apraxie ideatoire. [The problem of ideational apraxia.] Revue Neurologique, 102, 595-603. 
Heugten, C.M. van, Dekker, J., Deelman, B.G., Stehmann-Saris, F.C., Kinebanian, A. A diagnostic test for apraxia in stroke patients: internal consistency and diagnostic value. The Clinical Neuropsychologist: 1999, 13(2), 182-192

\section{TABLES}

Table 1. Schematic Presentation of the Relationship Between the Results of a Diagnostic Test and the Presence or Absence of a Disease.

\begin{tabular}{lcccc}
\hline & & \multicolumn{3}{c}{ Disease } \\
\cline { 3 - 4 } & & Present & Absent \\
\hline \multirow{2}{*}{ Test } & Positive & true-positive (a) & false-positive (b) & $\mathrm{a}+\mathrm{b}$ \\
& Negative & false-negative (c) & true-negative (d) & $\mathrm{c}+\mathrm{d}$ \\
\hline
\end{tabular}

Table 2. Demographic Data.

\begin{tabular}{|c|c|c|c|c|}
\hline \multirow[t]{2}{*}{ Group } & $\begin{array}{c}\text { Patients with apraxia } \\
\text { (patients) } \\
(n=44)\end{array}$ & $\begin{array}{l}\text { Patients without } \\
\text { apraxia } \\
\text { (patient controls) } \\
(n=35)\end{array}$ & \multicolumn{2}{|c|}{$\begin{array}{c}\text { Healthy elderly } \\
\text { (normal controls) } \\
(n=50)\end{array}$} \\
\hline & $n$ & $n$ & \multicolumn{2}{|c|}{$n$} \\
\hline \multicolumn{5}{|l|}{ Gender } \\
\hline Male & 20 & 14 & \multicolumn{2}{|c|}{11} \\
\hline Female & 24 & 21 & \multicolumn{2}{|c|}{39} \\
\hline \multicolumn{5}{|l|}{ Hand of preference } \\
\hline Right hand & 38 & 32 & \multicolumn{2}{|c|}{46} \\
\hline Left hand & 1 & 3 & \multicolumn{2}{|c|}{4} \\
\hline Unknown & 5 & - & \multicolumn{2}{|c|}{-} \\
\hline \multicolumn{5}{|l|}{ Institution } \\
\hline Hospital & 16 & 10 & \multicolumn{2}{|c|}{-} \\
\hline Rehab. center & 15 & 20 & \multicolumn{2}{|c|}{-} \\
\hline Nursing home & 13 & 5 & \multicolumn{2}{|c|}{50} \\
\hline \multicolumn{5}{|l|}{ CVA } \\
\hline Cerebral haemorrhage & 10 & 11 & & \\
\hline Cerebral infarction & 30 & 22 & & \\
\hline Unknown & 4 & 2 & & \\
\hline & $(S D)$ & $(S D)$ & $M$ & $(S D)$ \\
\hline Age (years) & $(10.8)$ & $(12.3)$ & 83.6 & $(6.0)$ \\
\hline Time since stroke (weeks) & $(5.0)$ & $(16.0)$ & & \\
\hline
\end{tabular}

Table 3. Homogeneity of the Apraxia Test.

\begin{tabular}{lccc}
\hline Subtest & Alpha & $H$ & Rho \\
\hline Demonstration & 0.95 & 0.76 & 0.95 \\
Imitation & 0.92 & 0.71 & 0.93 \\
Total & 0.96 & 0.72 & 0.97 \\
\hline
\end{tabular}


Heugten, C.M. van, Dekker, J., Deelman, B.G., Stehmann-Saris, F.C., Kinebanian, A. A diagnostic test for apraxia in stroke patients: internal consistency and diagnostic value. The Clinical Neuropsychologist: 1999, 13(2), 182-192

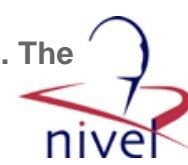

Table 4. Mokken Scale Analysis.

\begin{tabular}{lcc}
\hline Items & $M$ & Scalability coefficient \\
\hline hammer (1) & 2.59 & 0.78 \\
spoon (2) & 2.68 & 0.77 \\
key (1) & 2.75 & 0.72 \\
toothbrush (1) & 2.80 & 0.73 \\
scissors (2) & 2.95 & 0.70 \\
hammer (2) & 3.05 & 0.75 \\
eraser (3) & 3.25 & 0.74 \\
screwdriver (3) & 3.55 & 0.63 \\
saluting (4) & 4.41 & 0.67 \\
sticking out tongue (4) & 4.43 & 0.71 \\
blowing out a candle (4) & 4.43 & 0.69 \\
comb (3) & 4.48 & 0.78 \\
waving goodbye (4) & 4.50 & 0.60 \\
making a fist (4) & 4.82 & 0.71 \\
closing eyes (4) & 4.98 & 0.81 \\
Coefficient of Scalability H $=0.72$ & & \\
Coefficient of Reliability Rho =0.97 & & \\
\hline
\end{tabular}

Note. 1 = demonstration, verbal request; 2 = demonstration, visual presentation; 3 = demonstration, actual use; 4 = imitation of gestures.

Table 5. Results of the Test of Apraxia for the Apraxia Patients, the Patient Controls, and the Normal Controls.

\begin{tabular}{|c|c|c|c|c|c|c|c|c|c|}
\hline \multirow{2}{*}{$\begin{array}{l}\text { Group } \\
\text { Subtest }\end{array}$} & \multicolumn{3}{|c|}{$\begin{array}{c}\text { Patients with apraxia } \\
(n=42) \\
\text { (patients) }\end{array}$} & \multicolumn{3}{|c|}{$\begin{array}{l}\text { Patients without apraxia } \\
\qquad(n=35) \\
\text { (patient controls) }\end{array}$} & \multicolumn{3}{|c|}{$\begin{array}{l}\text { Healthy elderly } \\
\quad(n=50) \\
\text { (normal controls) }\end{array}$} \\
\hline & $M$ & $(S D)$ & Range & $M$ & $(S D)$ & Range & $M$ & $(S D)$ & Range \\
\hline Demonstration & 28.1 & $(20.0)$ & $0-54$ & 52.3 & $(3.5)$ & $43-54$ & 53.6 & $(1.7)$ & $48-54$ \\
\hline Imitation & 27.6 & (11.3) & $0-36$ & 35.7 & (1.0) & $32-36$ & 35.2 & $(1.5)$ & $30-36$ \\
\hline Total & 55.7 & $(29.0)$ & $0-90$ & 88.0 & (3.3) & $75-90$ & 88.8 & $(2.4)$ & $78-90$ \\
\hline
\end{tabular}


Heugten, C.M. van, Dekker, J., Deelman, B.G., Stehmann-Saris, F.C., Kinebanian, A. A diagnostic test for apraxia in stroke patients: internal consistency and diagnostic value. The

Clinical Neuropsychologist: 1999, 13(2), 182-192

Table 6. Score Distribution for the Three Groups of Participants.

\begin{tabular}{|c|c|c|c|}
\hline & Patients & Patient controls & Normal controls \\
\hline$<75$ & 27 & - & - \\
\hline 75 & 1 & 1 & - \\
\hline 76 & 1 & - & - \\
\hline 77 & - & - & - \\
\hline 78 & 2 & - & 1 \\
\hline 79 & 1 & - & - \\
\hline 80 & - & - & 1 \\
\hline 81 & 1 & 1 & - \\
\hline 82 & - & - & - \\
\hline 83 & 3 & 2 & - \\
\hline 84 & 1 & 1 & 1 \\
\hline 85 & 1 & 1 & - \\
\hline 86 & 2 & 1 & 2 \\
\hline 87 & - & 1 & - \\
\hline 88 & 2 & 3 & 10 \\
\hline 89 & - & 9 & 4 \\
\hline 90 & 2 & 15 & 31 \\
\hline$n$ & 44 & 35 & 50 \\
\hline
\end{tabular}

Note. Broken lines indicate the two cutoff scores presented in the text.

Fig. 1. Receiver Operator Characteristics curves for patients without apraxia (patient controls; solid line) and healthy elderly (normal controls; dashed line).

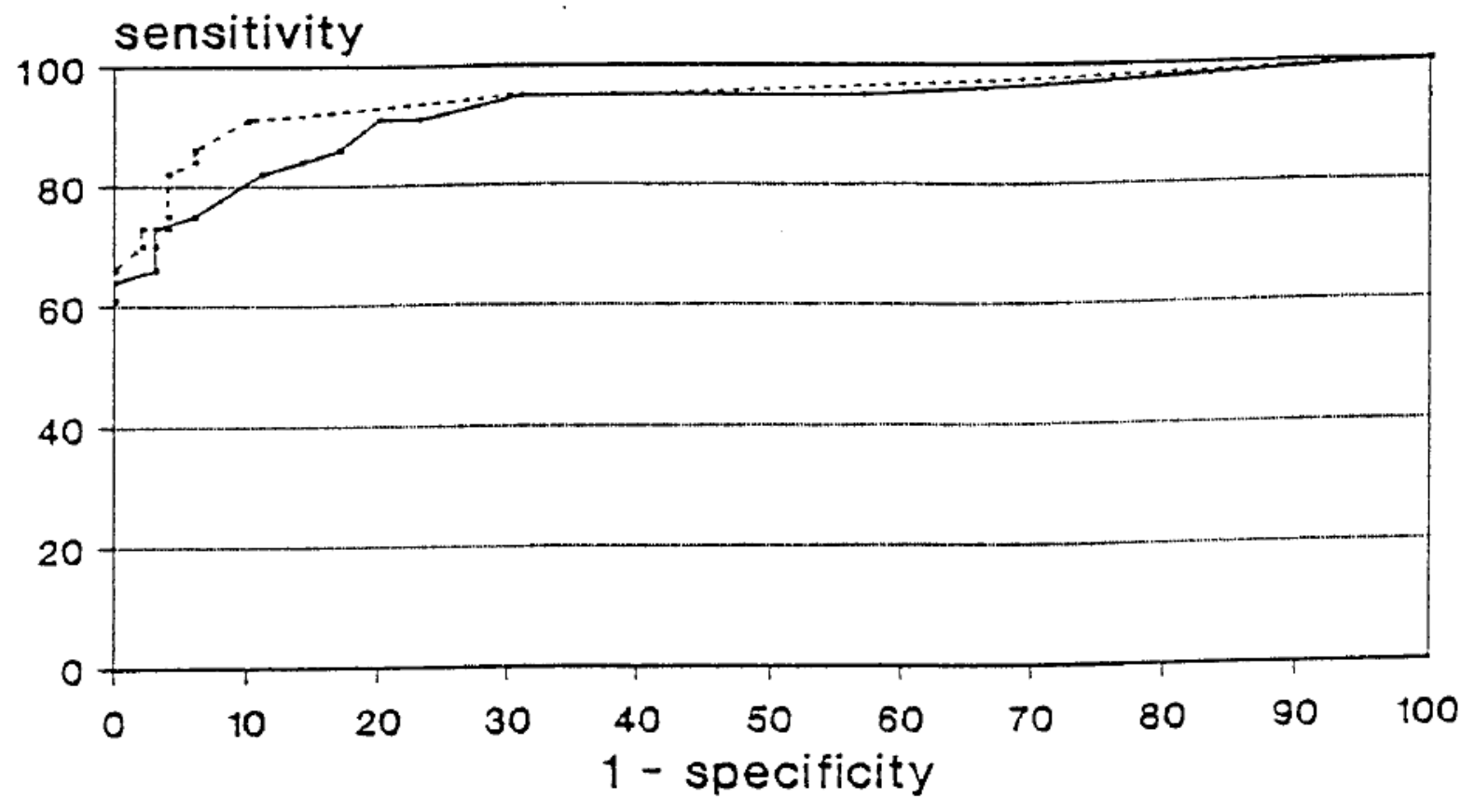

